\title{
Marital Satisfaction of Iranian Deaf Women: The Role of a Life Skills Training Program
}

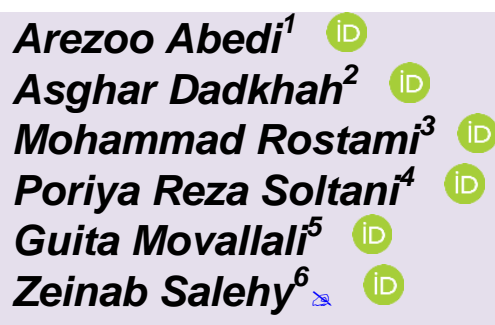

\begin{abstract}
\end{abstract}
Given that marital satisfaction and the factors influencing it are of high importance among deaf women, the present study aimed to examine the impact of life skills training on the marital satisfaction of deaf women in the Iranian Deaf Association (IDA). A multiple-baseline, single-case experimental design was conducted. The statistical population consisted of all deaf women in the IDA during 2014-2015. A total of 3 deaf women who met the inclusion criteria were selected using a purposeful sampling method. They participated in a 9-session life skills training program for 45 minutes a week. The instrument used in the present study was the 47-item version of the ENRICH Marital Satisfaction Scale (EMS). The data from repeated measures was processed using the trend comparison charts, and the clinical significance of the data was determined using the recovery rate formula. The results from the trend comparison charts, recovery rate formula, and visual analysis showed that the life skills training improved the marital satisfaction of the samples. According to the study findings, it can be concluded that life skills training improves the marital satisfaction among deaf women. Therefore, the method used in the present study can be recognized as an appropriate method in psycho-educational interventions for strengthening family foundation and improving marriage durability of deaf couples at the beginning of marriage.

Keywords: Marital satisfaction, Deaf women, Life skills.

\section{Contents}

1. Introduction

2. Methods.

3. Findings.

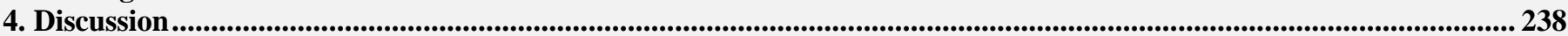

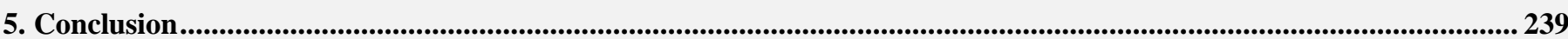

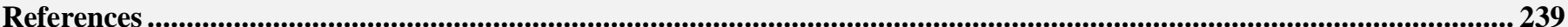

Citation | Arezoo Abedi; Asghar Dadkhah; Mohammad Rostami; Poriya Reza Soltani; Guita Movallali; Zeinab Salehy (2016). Marital Satisfaction of Iranian Deaf Women: The Role of a Life Skills Training Program. Asian Journal of Social Sciences and Management Studies, 3(4): 234-240. DOI:

$\operatorname{ISSN}(\mathbf{E})$ :

$\operatorname{ISSN}(\mathbf{P})$ : 10.20448/journal 500/2016.3.4/500.4.234.240 Crossref

Licensed: 2313-7401

Contribution/Acknowledgement: All authors contributed to the conception and design of the study. We would like to sincerely thank the officials of the

Funding: IDA and also the participant women who helped us with this study.

Competing Interests: This study received no specific financial support.

Transparency: The authors confirm that the manuscript is an honest, accurate, and transparent account of the study was reported; that no vital features of the study have been omitted; and that any discrepancies from the study as planned have been explained.

Ethical:

History:

Publisher: This study follows all ethical practices during writing. Received: 11 April 2016/ Revised: 10 May 2016/ Accepted: 27 May 2016/ Published: 10 June 2016 Asian Online Journal Publishing Group 


\section{Introduction}

According to the National Association of the Deaf (NAD), the term "deaf" refers to an individual with a hearing disability who is not capable of information processing (Patel, 2010). Deafness is an abnormal condition with extensive impacts on cognitive, emotional, and social development (Fellinger et al., 2012). This condition may lead to psychological disorders among deaf people because of their inability to have appropriate communication (Arlinger, 2003). Some research has indicated that mental-health problems are high among deaf people, and some other research has reported a prevalence rate of $40 \%$ mental-health disorders among deaf people (Hindley et al., 1994). Deafness can have unpleasant developmental outcomes in relational, cognitive, emotional, and social areas (Kral and O'Donoghue, 2010). In other words, an impairment in understanding and using language may lead to relational problems, and this, at the same time, can lead to frustration and other problems, such as aggressive behavior, anxiety, and social isolation, resulting in a decrease in opportunities for development of language and communication skills, such as having relationship with peers and adults (Edwards et al., 2008).

In addition to relational problems, deaf people may have problems with social competence and life skills (Movallali et al., 2012). Hearing loss can have negative impacts on marital relationship, and endanger a couple's relationship, therefore, it is necessary to increase the level of awareness in this group, and provide education and consultation for them (Kooser, 2011). One of the most important aspects of a marital system is the satisfaction experienced by a couple. Marital satisfaction is a positive and enjoyable attitude in a couple that is formed based on different aspects of marital life, such as relationship, personality, conflict resolution, financial situations, sexual relationship, and children (Pourheydari et al., 2013). Numerous factors affect marital satisfaction, including the level of knowing each other before marriage, cultural and financial similarities, healthy personality and mood, common values, attitudes, interests, preferences, and goals; similarities between couple's families, level of interference in others work, level of family management, level of family happiness, level of problems, and stresses (Abbasi et al., 2011). Previous research has shown that many factors have a role in marital satisfaction, and among these factors is seeking a companion (Aida and Falbo (1991); Karney and Frye (2002)) being good-tempered (Blum and Mehrabian, 1999) trustfulness, love, and faithfulness (Roizblatt et al., 1999) intimacy and avoidance of aggressive control (Goodman, 1999) interactions and showing interest (love and affection), empathy, sexual satisfaction, cooperation with each other, an accurate knowledge of feelings, understanding feelings and their origin, and an appropriate management of feelings (Kaveh, 2011). Human beings are social creatures, and tend to have close and intimate relationships with each other. A good relationship provides the greatest marital satisfaction for a couple (Kooser, 2011). Relationship is usually considered as an important factor in the level of marital satisfaction that a couple may feel. Therefore, relationship skills training is a main focus in many marriage enrichment programs Hosseinkhanzadeh and Yeganeh (2013b); Kooser (2011). Deafness affects a couple's relationship, and may lead to a reduction in affective and physical intimacy, therefore, hearing loss brings negative outcomes to marital satisfaction (Kooser, 2011). The common communicational problems among deaf couples, when one or both are deaf, include wrong and incongruent interpretation of issues and problems, lack of education, and weak and limited skills regarding the management and handling of life conflicts and problems (Thew, 2011). According to global statistics, the rate of divorce among couples with partial hearing loss is the same as normal couples, but it is four times more prevalent among deaf people (Kooser, 2011). Some of the methods applied to reduce a couple's relationship problems are providing educational programs, teaching appropriate relationship techniques, and providing trained deaf teachers (Thew, 2011). Among these, life skill training is an educational program useful for improving the quality of relationship and marital satisfaction (Hosseinkhanzadeh and Yeganeh, 2013b). Life skills training in couples, not only have an impact on the improvement of relationship quality, but also has a significant role in the improvement of mental and general health, reduction of family stress, increase of social acceptance, and even, preventing suicide (Khadivi et al., 2005; Abbasi et al., 2011). Although few studies have directly addressed the impact of life skills training on the improvement of marital satisfaction among deaf couples, the effectiveness of this method has been shown by some similar studies on hearing people. For example, Hosseinkhanzadeh and Yeganeh (2013b) conducted a study on marital satisfaction of women. They concluded that life skills' training improves marital satisfaction. Pourheydari et al. (2013) found that life skills training leads to sexual and marital satisfaction among young couples. Also Pourheydari et al. (2013) in line with Abbasi et al. (2011) showed that life skills training increases marital satisfaction. Other studies confirmed the effectiveness of relationship skills in the improvement of marital satisfaction, but most of the studies have been conducted on hearing couples.

Given that not only is deafness a sensory inability, but also it is an impairment that leads to difficulties in interpersonal relationships and problems in mental health Alexander et al. (2012); Fellinger et al. (2012) mental health care is essential for deaf people. However, it is estimated that only $2 \%$ of deaf adults have ever received mental health care (Rostami et al., 2014). Moreover, since deaf couples experience problems in their lives and relationships which can potentially have negative effects on their relationship and level of marital satisfaction, it is necessary to take steps in order to reduce their problems and mental and relationship difficulties. Studies conducted on deaf women are limited and their marital satisfaction is neglected. Therefore, the present study aimed to examine the effectiveness of life skills training in marital satisfaction of deaf women.

\section{Methods}

In the present study, a multiple-baseline, single-case experimental design was used. The reason for selecting this method is that it is difficult to have group training with deaf people, and they need a face to face relationship in order to better learn and understand the materials; therefore, the training was conducted individually. The statistical population included all deaf women in Iranian Deaf Association (IDA), in 2014-2015. A total of 3 deaf women who met the inclusion criteria were selected using a purposeful sampling method.

The instrument used in the present study was the ENRICH Marital Satisfaction Scale (EMS), developed by Olson et al. (1987). The purpose of this questionnaire is to examine relationship strengths and work on areas of marital life. It is also used for diagnosis of the couples who need consultation and strengthening of relationship. The 
EMS has also been used as a valid instrument in numerous studies to assess marital satisfaction. There are 115 -item and 125-item versions of the EMS. In Iran, a 47-item version of the EMS has been standardized. In the present study, the 47 -item version of the questionnaire is used which includes 9 subscales namely marital relationship (items 6,13 , 23, 32, and 41), personality issues (items 2, 4, 12, 22, and 40), conflict resolution (items 7, 14, 24, 33, and 42), financial management (items 8, 15, 16, 25, and 34), leisure activities (items 9, 17, 26, 35, and 43), sexual relationship (items 10, 18, 27, 36, and 44), children and parenting (items 11, 19, 28, 37, and 45), family and friends (items 20, 29, 31,38 , and 46), and religious orientation (items 5, 21, 30, 39, and 47). The items are rated on a 5-point Likert scale ranging from 1 (totally agree) to 5 (totally disagree). The total score of a person shows their level of marital satisfaction. In addition, some items are reverse-scored (Motadyn et al., 2012).

\subsection{Validity and Reliability}

Olson et al. (1987) reported a Cronbach's alpha coefficient of 0.92 for the EMS. In the Farsi version of this questionnaire, Cronbach's alpha was obtained at 0.82 for women and 0.92 for men that shows high internal consistency of this questionnaire. Correlation coefficient between the scores of subjects on two occasions with three weeks interval was 0.88 for all the subjects (Hosseinkhanzadeh and Yeganeh, 2013a).

\subsection{Procedure}

First of all, a list of the women who met the inclusion criteria was obtained with the help of the head of the IDA, and then, participants were invited to the study. Participants were informed about the goals and procedures of the study, and they completed a consent form. The first baseline was measured 20 days before the intervention (A1), the second baseline was measured 10 days before the intervention (A2), and the third baseline was measured in the preliminary session, using the EMS (A3). The participants who had a low mean score on the EMS (lower than 150) were selected for intervention. Deaf women, who met the requirements, received the life skills training in 9 sessions (45 minutes per session). Given that the deaf people have many problems in reading and writing, and specially in understanding the meaning of words, we tried to present the materials in a simple way. We also used pictures in order to help them better understand the materials. Because of the importance of a mutual understanding between the participants and researchers, experts in sign language helped the researcher have communication with deaf women. During the 9 intervention sessions, the sample group were measured at the start of the third session (B1), at the start of the sixth session (B2), and at the end of the ninth session (B3), using the EMS. After the end of the interventions, a 4-week follow-up measurement was conducted (F1). It is worth to say that the life skills training was conducted individually. The data from repeated measures was processed using the trend comparison charts and visual analysis, and the clinical significance of the data was calculated using the recovery rate formula (Hamidpour et al., 2011).

Recovery rate $=\underline{100 \times \text { Pre-test score }- \text { Post-test score }}$

Pre-test score

If the recovery rate is at least 50, the results can be regarded as significant (Hamidpour et al., 2011). The inclusion criteria were as follows: 1- being a deaf woman, 2- at least four years of marital life, 3- being able to read and write, and 4- a score on the EMS lower than 150 (which indicate marital dissatisfaction). The exclusion criteria were as follows: 1 - using any other form of psychotherapy or consultation services during the time of study, 2- being absent for three sessions, 3- withdrawal or unwillingness to continue the study, 4- having another disability beside deafness, and 5- being divorced. The ethical issues considered in this study were as follows: deaf women took part in the life skills training sessions voluntarily, their informed consent for participation in the study was obtained, the sessions were free of charge, all information about the participants remained confidential, the participants were allowed to leave the study at any time, the topic, goals, and procedure of the study were explained to the IDA's officials and study participants, and the officials were reassured that they would be informed about the study results, in a group manner, and in a way that the participants remain anonymous (their real name was not mentioned in the study, and they were given pseudonyms), and putting pressure on deaf women or putting them at mental or physical risks were avoided.

\subsection{The Content of Training Sessions}

The present treatment design is derived from the studies by Khajeddin et al. (2010) and books written by McKay and Kleinke (1991) and (Kleinke, 1991; McKay et al., 2006; Khajeddin et al., 2010; Kaveh, 2011). Given that the study participants were deaf women, we used pictures, role play, and understandable sentences in presenting the training. We also got help from an expert in sign language in order to facilitate the communications. The pictures were taken from two books by Glickman (2008); Glickman and Gulati (2003).

The structure of sessions is as follows:

\begin{tabular}{l|l}
\hline Session Number & Content Session \\
\hline First session & $\begin{array}{l}\text { Introduction and making rapport, Introduction of the researcher as a teacher, } \\
\text { Introduction of the members and goals, Introduction of the training workshop, } \\
\text { Participants' commitments in the sessions; and a review of the necessity of learning } \\
\text { life skills training and its impact on marital life }\end{array}$ \\
\hline Second session & $\begin{array}{l}\text { A review of the previous session's materials, Self-awareness skill training, } \\
\text { Mentioning the characteristics of self-aware people, Mentioning the benefits of self- } \\
\text { awareness, A summary of the materials, Giving feedbacks, Giving assignments. }\end{array}$ \\
\hline
\end{tabular}




\begin{tabular}{l|l}
\hline Third session & $\begin{array}{l}\text { A review of the previous session's materials, Evaluating the previous assignment, } \\
\text { Empathy skills training, Making the couples familiar with the empathy-related } \\
\text { concepts and impact of empathy on marital life and relationship, Giving } \\
\text { assignments. }\end{array}$ \\
\hline Fourth session & $\begin{array}{l}\text { A review of the previous session's materials, Evaluating the previous assignments; } \\
\text { Teaching relationship skills, Relationship with satisfaction, Marital adjustment, and } \\
\text { the ways of having a good relationship. }\end{array}$ \\
\hline Fifth session & $\begin{array}{l}\text { A review of the previous session's materials, Evaluating the previous assignments, } \\
\text { Teaching anger management skills, Negative effects of anger on health, Negative } \\
\text { effects of anger on marital satisfaction and couples' relationship, Teaching anger- } \\
\text { control skill, Giving assignments. }\end{array}$ \\
\hline Sixth session & $\begin{array}{l}\text { A review of the previous session's materials, Evaluating the previous assignments, } \\
\text { Teaching decision-making skills, The outcomes of appropriate and inappropriate } \\
\text { decision-making for marital life, A summary of materials, Giving feedbacks, Giving } \\
\text { assignments. }\end{array}$ \\
\hline Eighth session & $\begin{array}{l}\text { A review of the previous session's materials, Evaluating the previous assignments, } \\
\text { Teaching critical thinking skills and decisiveness, The stages of these skills, The } \\
\text { important role of critical thinking skills and decisiveness in marital relationship. }\end{array}$ \\
\hline $\begin{array}{l}\text { A review of the previous session's materials, Evaluating the previous assignments, } \\
\text { Teaching problem-solving skills, The stages of this skill, The role of problem- } \\
\text { solving skills in resolving marital conflicts, The important role of this skill in } \\
\text { overcoming marital life problems. }\end{array}$ \\
\hline $\begin{array}{l}\text { A summary of materials discussed in the previous sessions, Thanking and } \\
\text { acknowledging the participants, Receiving feedbacks for future works. }\end{array}$ \\
\hline
\end{tabular}

\section{Findings}

In this section, the data is analyzed in a case study such as this research. Charting method is the most useful and acceptable method for the interpretation of the results (Vakil et al., 2011). Furthermore, demographic characteristics of participants and percentage of recovery were shown and the continuation of marital satisfaction scores in deaf women was measured 7 times including three baseline in twenty days which is ten days before the intervention and in the meeting session before the start of the training, in the process of intervention the third, sixth, ninth sessions and finally measuring a follow-up after four-weeks and in the form of tables and graphs as presented below.

\begin{tabular}{l|l|l|l|l|l|l}
\hline Table-1. Demographic characteristics of participants \\
\hline Participants & Age & $\begin{array}{l}\text { During } \\
\text { marriage }\end{array}$ & $\begin{array}{l}\text { Number of } \\
\text { children }\end{array}$ & $\begin{array}{l}\text { Level of } \\
\text { education }\end{array}$ & $\begin{array}{l}\text { Participants } \\
\text { jobs }\end{array}$ & Husband \\
\hline First & 40 years old & 12 years & Two children & $\begin{array}{l}\text { Associate } \\
\text { Degree }\end{array}$ & housewife & Deaf \\
\hline Second & 38 years old & 10 years & A child & Diploma & housewife & Deaf \\
\hline Third & 35 years old & 9 years & A child & Diploma & housewife & Deaf \\
\hline Source: Olson et al. $(1987)$. &
\end{tabular}

Table-2. Recovery percentage of marital satisfaction for participants in life skills training sessions

\begin{tabular}{l|l|l|l}
\hline Marital satisfaction & First participant & Second participant & Third participant \\
\hline Baseline & 138 & 119 & 120 \\
\hline Final score & 212 & 189 & 186 \\
\hline Recovery percentage & $54 \%$ & $59 \%$ & $56 \%$ \\
\hline Source: Olson et al. (1987).
\end{tabular}

Table 2 shows the recovery rate of marital satisfaction among deaf women. The highest recovery rate is for the second participant (59\%) and the lowest recovery rate is for the first participant (54\%).

\section{marital satisfaction}

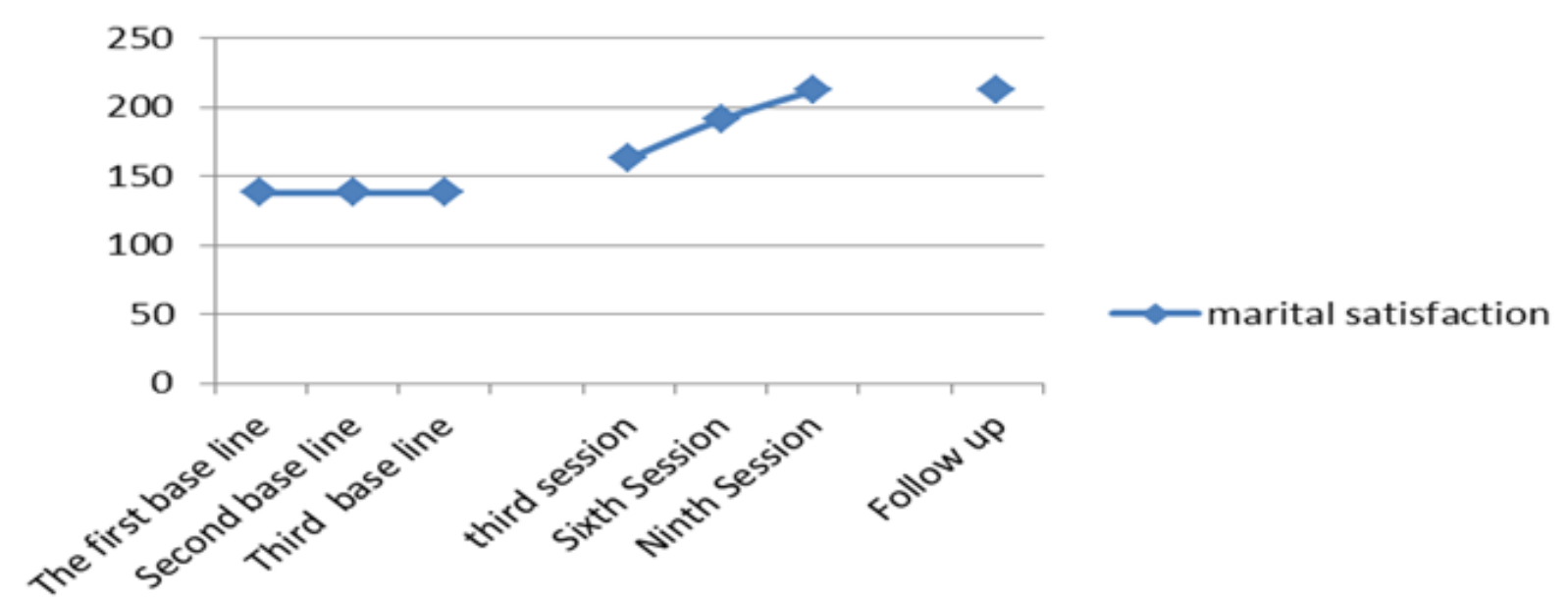

Source: Olson et al. (1987)

Chart-1. Recovery trend in the scores of the first participant on marital satisfaction 


\section{marital satisfaction}

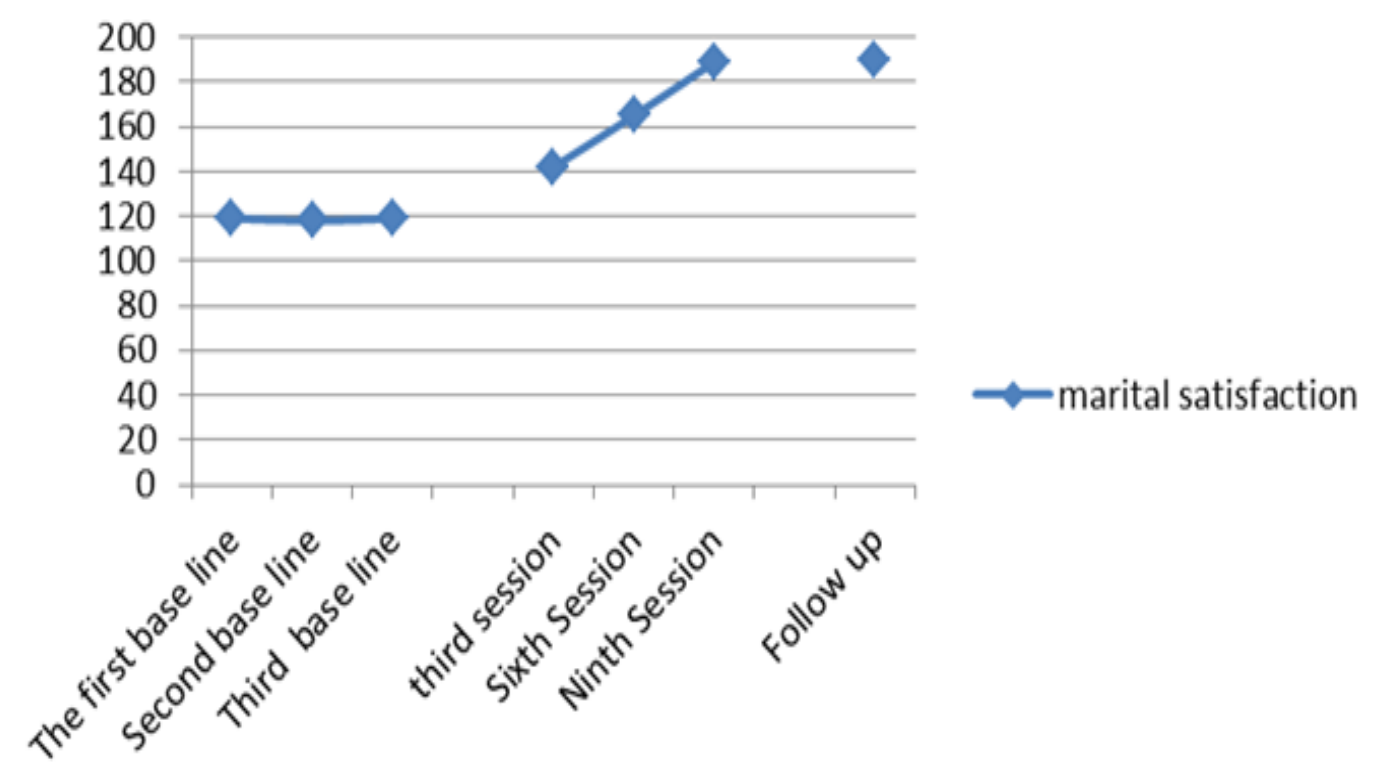

Chart-2. Recovery trend in the scores of the second participant on marital satisfaction Source: Olson et al. (1987)

\section{marital satisfaction}

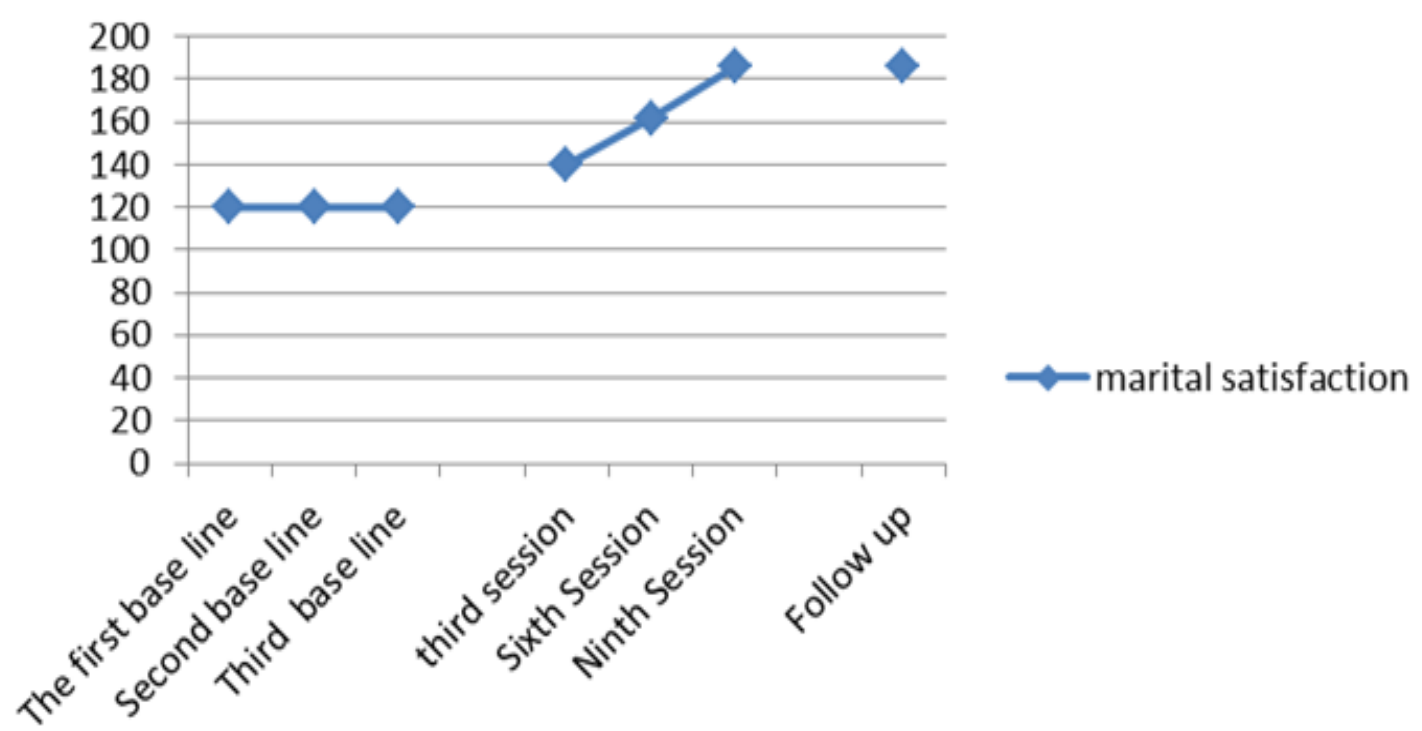

Chart-3. Recovery trend in the scores of the third participant on marital satisfaction Source: Olson et al. (1987)

Charts 1,2, and 3 show that the score of participants on marital satisfaction increased significantly under the life skills training intervention. As it is illustrated, the scores on marital life satisfaction in the first, second and third baselines indicate a low total score on the EMS. The first change is seen after three sessions of life skills training. Therefore, in the third, sixth, and ninth sessions, there was an increasing trend in the scores of all participants on marital satisfaction. This increase is also noticeable in the follow-up session.

\section{Discussion}

The goal of the present study was to examine the effectiveness of life skills training on marital satisfaction of deaf women. After conducting the life skills training intervention for deaf women during 9 sessions, and administrating the EMS for 7 times, in 3 baselines before intervention, 3 measurements during the process of training, and in a 1-month follow-up after the training, the results indicated that the life skills training was effective in the improvement of marital satisfaction among deaf women. Given that the scores of participants on marital satisfaction were low or constant in the 3 baselines, and there was an increase in the scores after the intervention, it can be concluded that this increase resulted from the intervention. The results of this study are consistent with the results of a previous study by Hosseinkhanzadeh and Yeganeh (2013a) and Abbasi et al. (2011) that showed the effectiveness of life skills training in the improvement of marital satisfaction (Abbasi et al., 2011; Hosseinkhanzadeh and Yeganeh, 2013a). The study results are also in line with the studies by Field and Lipkin (2004) and Ronan et al. (2004). Field et al conducted trainings on effective inter-personal relationship, problem-solving, and decision making skills with women and men who had problems in their marital life, for 3 months. The results showed an increase in marital satisfaction. In addition, Ronan et al. (2004) in their study, taught a program consisting of angermanagement, anger reduction, problem-solving, and skills for coping with severe conflicts. The results indicated the positive impact of training and a reduction in marital conflicts (Field and Lipkin, 2004; Ronan et al., 2004). In order to explain this result, it can be pointed out that through an increase of self-awareness, life skills can lead to an awareness of personal needs, expectations, and desires. This awareness, in turn, is presented to the partner through 
relationship skills resulting in a mutual understanding. This, in turn, can lead to the improvement of marital satisfaction. Moreover, acquiring such skills as empathy, anger-control, and problem solving, help a couple to understand the deficits and problems of each other, and by avoiding anger, giving empathy, and consultation, look for right solutions and increase their marital satisfaction.

It can be argued that if a person learns to express their feelings decisively, this helps them to express their feelings toward their partner, and in this way, improve their own mental illness Expressing feelings in a positive way and without aggression and confrontation gradually helps couples get closer to each other and have a more intimate relationship. In addition, by acquisition of decision-making and problem-solving skills, a couple will be able to use more appropriate strategies when facing problems in marital life, or needing to take very important decisions; and this leads to an increase in marital satisfaction. People, who have learned the problem-solving skills, face problems instead of withdrawal or running away from them. Many research studies such as Baron et al. (2007) have shown that an increase in aggression and anger decreases marital adjustment and satisfaction, and causes people to feel less satisfied with their lives. Regarding the importance of this skill, it can be suggested that aggressive responses of a couple have negative effects on their relationship, lead to shortcomings in the relationship, reduce marital adjustment and satisfaction, and prevent the couple from expressing their feelings decisively. This, in turn, leads to a decrease in the honesty between them. Another important life skill that has much impact on marital adjustment and satisfaction is empathy. Waldinger et al. (2004) believed that happy and compatible couples show more empathy than incompatible couples. This skill helps a couple to feel that their partner understands them, and this leads to a feeling of happiness and satisfaction with marital life. Therefore, we can argue that when a couple masters the essential life skills, this keeps the balanced function of the family in face of unpleasant situations, and helps the family to reach its goals which improves marital satisfaction and adjustment (Waldinger et al., 2004); (Marioles and Allen, 1996). Stated that if a couple trust each other, have similar internal desires, discuss calmly, and change their attitudes, they will experience the highest marital satisfaction. According to the results of an interview with participant couples, the creative thinking skills training had helped them to go further than common and stereotypical methods, and create explanations or solutions specific to them in the face of life problems. They also learned not to conform easily to the environment around them, and live consciously and independently by using critical thinking skills. In addition, other behavioral strategies of life skills training invoked cognitive responses that influenced marital satisfaction of couples through the subsequent interactive behavior. The scores on the EMS and clinical observations indicated a low marital satisfaction among deaf women. They complained about relationship problems with their partner during sessions, and stated that they were not able to agree on a solution. Therefore, the life skills training (self-awareness, empathy, relationship, anger-management, decision-making, problem-solving, and creative and critical thinking) improved the marital satisfaction of participants. In fact, self-awareness helped them to realize their own and their partner's needs, expectations, and desires, and expresses these to their partner. Decision-making, empathy, problem-solving, and anger management skills helped them to solve problems by consulting with each other. Moreover, creative and critical thinking skills helped them to think about issues and problems, and not easily conform to the people around them. Therefore, the overall learning of these skills had a significant impact on the marital satisfaction of deaf women.

\section{Conclusion}

The findings of the present study confirmed the impact of life skills training on the improvement of marital satisfaction among deaf women. Therefore, the methods in this study can be regarded as appropriate methods in psycho-educational interventions for consolidating family foundation and improving marriage durability at the beginning of marriage for deaf couples. The study results can also be used by family consultants, psychologists, and experts who work with women and deaf couples to solve marital problems resulting from a lack of life skills. The findings can also be useful in family consultation centers and centers for the deaf. One limitation of this study was the small sampling group. In fact, since it is difficult to have group training with deaf people, and they need a face to face relationship in order to better learn and understand, the training was done individually and with a small sampling group. Beside their advantages, these kinds of studies have some limitations such as generalizability. Moreover, the present study was conducted on deaf women, therefore, it is suggested that the study be replicated with deaf men.

\section{References}

Abbasi, A., N. Jalilpour, A. Kamkar, G. Zadehbaghri and F. Mohamed, 2011. The effects of life skills training on maritalsatisfaction of married women: A case studyin dogonbadan, Iran. Armaghane-Danesh, Yasuj University of original article. Medical Sciences Journal YUMSJ, 6(16): 587-594.

Aida, Y. and T. Falbo, 1991. Relationships between marital satisfaction, resources, and power strategies. Sex Roles, 24(1-2): 43-56.

Alexander, A., P. Ladd and S. Powell, 2012. Deafness might damage your health. Lancet, 379(9820): 979-981.

Arlinger, S., 2003. Negative consequences of uncorrected hearing loss--a review. International Journal of Audiology, 42(Suppl 2): 17-20.

Baron, K.G., T.W. Smith, J. Butner, J. Nealey-Moore, M.W. Hawkins and B.N. Uchino, 2007. Hostility, anger, and marital adjustment: Concurrent and prospective associations with psychosocial vulnerability. Journal of Behavioral Medicine, 30(1): 1-1.

Blum, J.S. and A. Mehrabian, 1999. Personality and temperament correlates of marital satisfaction. Journal of Personality, 67(1): 93-125.

Edwards, L., S. Crocker and S.R. Crocker, 2008. Psychological processes in deaf children with complex needs: An evidence-based practical guide. London: Jessica Kingsley Publishers.

Fellinger, J., D. Holzinger and R. Pollard, 2012. Mental health of deaf people. Lancet, 379(9820): 1037-1044.

Field, F. and M. Lipkin, 2004. Teaching senior on cologest life skills: Result from phasel of a compernansive long itudinal programin the United Kingdom. Jornal of Clinical Oncolgogy, 16(5): 135-157.

Glickman, N., 2008. Cognitive-behavioral therapy for deaf and hearing persons with language and learning challenges. New York: Routledge. Glickman, N.S. and S. Gulati, 2003. Mental health care of deaf people: A culturally affirmative approach. New York: Routledge.

Goodman, C., 1999. Intimacy and autonomy in long term marriag. Journal of Gerontological Social Work, 32(1): 83-97.

Hamidpour, H., B. Dolatshahi, A. Poorshahbaz and A. Dadkhah, 2011. Performance schema therapy in the treatment of patients withgeneralized anxiety disorder. Psychiatry and Clinical Psychology Iran, 4(16): 420-431. 
Hindley, P.A., P.D. Hill, S. McGuigan and N. Kitson, 1994. Psychiatric disorder in deaf and hearing impaired children and young people: A prevalence study. Journal of Child Psychology and Psychiatry, 35(5): 917-934.

Hosseinkhanzadeh, A.A. and T. Yeganeh, 2013a. The effects of life skills training on marital satisfaction. Procedia-Social and Behavioral Sciences, 84: 769-772.

Hosseinkhanzadeh, A.A. and T. Yeganeh, 2013b. The effects of life skills training on marital satisfaction. Procedia- Social and Behavioral Sciences, 84: 769-772. DOI http://dx.doi.org/10.1016/j.sbspro.2013.06.643.

Karney, B.R. and N.E. Frye, 2002. But we've been getting better lately: Comparing prospective and retrospective views of relationship development. Journal of Personality and Social Psychology, 82(2): 222-238.

Kaveh, F.Z., 2011. The effect of life skills training on satisfaction and marital adjustment of married women, rural city Farsan. Journal of Counseling and Psychotherapy Family, 3(2): 373-387.

Khadivi, Z., M. Moezi, M. Shakeri and M. Borjian, 2005. The effect of life skills training on preventing suicide attempts in women in Ardal city. Illam Journal of Medical Sciences, 13(1): 13-20.

Khajeddin, N., F. Riahi, M. Salehi-Veysi and S. Izadi-Mazidi, 2010. Effects of life skills workshops on marital satisfaction. Iranian Journal of Psychiatry and Behavioral Sciences, 4(2): 42-46.

Kleinke, C.L., 1991. Coping with life challenges. Pacific Grove, Calif: Brooks/Cole,

Kooser, C., 2011. Hearing loss and its impact on marriage: A Clinician's Perspective, Unpublished.

Kral, A. and G.M. O'Donoghue, 2010. Profound deafness in childhood. New England Journal of Medicine, 363(15): 1438-1450.

Marioles, N.S. and L.H. Allen, 1996. The relationship between psychological type and couples satisfaction and behavior. Virginia: Common Wealth University.

McKay, M., P. Fanning and K. Paleg, 2006. Couple skills: Making your relationship work. Oakland, CA: New Harbinger Publications.

McKay, M. and C.L. Kleinke, 1991. A biopsychosocial and cross-culturalapproach to the management. New Yorl Munchen/ Berlin: Waxmann Munster.

Motadyn, M., M.H. Asaysh and M. Eftekhari, 2012. The relationship between attachment styles and marital satisfaction in married students. Second National Conference on Psychology, Psychology of Family (2).

Movallali, G., A.S. Jalil and M. Ashouri, 2012. The effectiveness of life skills training on the social competency of hearing-impaired students. Journal of Hearing, Speech and Language, 1(1): 41-48.

Olson, D.H., D.G. Fournier and J.M. Druckman, 1987. Counselor's manual for prepare/ENRICH. Minneapolis, MN: Prepare /ENRICH.

Patel, J.V., 2010. Risk of ill health is increased. British Medical Journal, 1(1): 341-344.

Pourheydari, S., F. Bagherian, J. Bahadorkhan and M. Doustkam, 2013. The effects of life skills training on marital and sexual satisfaction of young couples. JSR, 14(51): 14-22.

Roizblatt, A., F. Kaslow, S. Rivera, T. Fuchs, C. Conejero and A. Zacharias, 1999. Long lasting marriages in Chile. Contemporary Family Therapy, 21(1): 113-129.

Ronan, G.F., L.E. Dreer, K.M. Dollard and D.W. Ronan, 2004. Violent couples: Coping and communication skills. Journal of Family Violence, 19(2): 131-137.

Rostami, M., B. Bahmani, V. Bakhtyari and G. Movallali, 2014. Depression and deaf adolescents: A review. Iranian Rehabilitation Journal, 12(1): 43-53.

Thew, D., 2011. Seasonal affective disorder, depression and communication /relationship programs in deaf people. National Institute for the Deaf.

Vakil, N.A., P. Mohammadkhani and B. Dolatshahi, 2011. A comparison between enhonced cognitive behavioral coupletherapy andintegrative behavioral couple therapy in reducing marital distress andincreasing marital satisfaction. Journal of Modern Psychological Research, 22(6): 149-175.

Waldinger, R.J., M.S. Schulz, S.T. Hauser, J.P. Allen and J.A. Crowell, 2004. Reading others emotions: The role of intuitive judgments in predicting marital satisfaction, quality, and stability. Journal of Family Psychology, 18(1): 58-71. 